\title{
Waterborne Polyurethane Coatings with Covalently Linked Black Dye Sudan Black B
}

\author{
Tao Wang ${ }^{(D)}$, Wei Sun, Xingyuan Zhang * (1) , Haiyan Xu and Fei Xu \\ CAS Key Laboratory of Soft Matter Chemistry, Department of Polymer Science and Engineering, \\ University of Science and Technology of China, Hefei 230026, China; wt0510@mail.ustc.edu.cn (T.W.); \\ kdsw@mail.ustc.edu.cn (W.S.); sa12226023@mail.ustc.edu.cn (H.X.); puglobe@mail.ustc.edu.cn (F.X.) \\ * Correspondence: zxym@ustc.edu.cn; Tel.: +86-0551-6360-7484
}

Received: 17 September 2017; Accepted: 26 October 2017; Published: 28 October 2017

\begin{abstract}
Colored waterborne polyurethanes have been widely used in paintings, leathers, textiles, and coatings. Here, a series of black waterborne polyurethanes (WPUs) with different ratios of black dye, Sudan Black B (SDB), were prepared by step-growth polymerization. WPU emulsions as obtained exhibit low particle sizes and remarkable storage stability at the same time. At different dye loadings, essential structural, statistical and thermal properties are characterized. FTIR (fourier transform infrared) spectra indicate that SDB is covalently linked into waterborne polyurethane chains. All of the WPUs with covalently linked SDB show better color fastness and resistance of thermal migration than those with SDB mixed physically. Besides, WPUs incorporated SDB covalently with different polymeric diols, polytetramethylene ether glycol (PTMG), polypropylene glycol (PPG), poly-1, 4-butylene adipate glycol (PBA) and polycaprolactone glycol (PCL), were prepared to obtain different properties to cater to a variety of practical demands. By a spraying method, the black WPUs can be directly used as metal coatings without complex dyeing process by simply mixing coating additive and other waterborne resins, which exhibit excellent coating performance.
\end{abstract}

Keywords: Sudan black B; waterborne polyurethane; polymeric dye; metal coatings

\section{Introduction}

Recently, colored polymeric dyes, especially back dyes, have been widely used in textiles, ink, coatings, leathers and photoelectric materials [1-6]. Generally, the strategy on developing polymeric dyes is usually to physically mix micromolecular dyes with polymeric matrices by ionic bonds, hydrogen bonds or Van der Waals force. However, there is a thorny problem that, with time elapsing, the dyes may migrate and aggregate, leading to color fading of materials due to the noncovalent bond interaction between matrices and dyes. Moreover, plenty of black dyes containing benzidine groups have a potential risk to humans and environment [7-9]. Therefore, low-toxic and environmentally friendly materials are of great importance.

An effective method to solve the problem is to chemically link micromolecular dyes to polymeric main chains [10,11] or side chains [12] by various chemical reactions. Generally speaking, polymeric dyes are safe and nontoxic for humans because they cannot be absorbed by skin owing to their large molecular dimension, excellent chemical and thermal stability. Moreover, polymeric dyes with tunable molecular structures exhibit great compatibility and strong binding force with fibers. In the past decades, many researchers have been devoted to investigating polymeric dyes. For example, in the 1980s, Marechal et al. studied systemically on polymeric dyes for the first time [13-15]. Recently, many polymeric dyes have been prepared by incorporating chromophores into common polymeric materials, such as polyacrylates, polyethlene, polyamide and polymaleic acid, to enlarge the application fields [12,16-19]. Waterborne polyurethanes (WPUs) as a kind of highly versatile polymeric material 
with excellent environment-friendly and low-toxic properties have been widely used as coatings, leathers, adhesives, and paints [20-22]. By a facile polycondensation reaction, a lot of colored WPUs are developed by chemically incorporating micromolecular dyes into polyurethane matrices, which could show great migration resistance and color fastness while not obviously changing the intrinsic characteristic of the polymer materials [23-26]. However, there are few of reports on black dyes because of incomplete purity of black for purely organic dyes.

Here, A series of novel black WPU dyes with different ratios of black dye, Sudan Black B (SDB), were prepared by polycondensation reaction, which exhibit good migration resistance, storage stability and heat resistance, while, at the same time, not causing significant aggregation/phase separation between micromolecular dyes and WPU matrices. Besides, Black WPUs with different polymeric diols are also investigated serving as black metal coatings, which exhibit excellent coating performance.

\section{Experimental}

\subsection{Materials}

Isophorone diisocyanate (IPDI) was purchased from Bayer Co., Ltd. (Leverkusen, Germany) Polytetramethylene ether glycol (PTMG, Mn = 2000) and polypropylene glycol (PPG, Mn = 2000) were supplied by Mitsubishi Co., Ltd. (Tokyo, Japan). Poly-1,4-butylene adipate glycol (PBA, Mn = 2000) was obtained from Qingdao Xinyutian Chemical Co., Ltd. (Qingdao, China). Polycaprolactone glycol (PCL, Mn = 2000) was supplied by Daicel Corporation (Kobe, Japan). All of the glycols were thoroughly dehydrated at $110^{\circ} \mathrm{C}$ before use. 2, 2-dimethylolpropionic acid (DMPA) and Sudan black B (SDB, C.I.26150) were purchased form Aladdin Reagent Co., Ltd. (Shanghai, China). 1,4-Butanediol (BDO), Dibutyltin dilaurate (DBTDL), triethylamine (TEA), were purchased from Sinopharm Chemical Reagent Co., Ltd. (Hefei, China). BYK-025 and BYK-331 were acquired from BYK-Chemie GmbH Co., Ltd. (Wesel, Germany). ACRYSOL ${ }^{\mathrm{TM}} \mathrm{RM}-8 \mathrm{~W}$ was provided by Rohm\&Haas Co., Ltd. (Philadelphia, America). Other reagents were obtained from Energy Reagent Co., Ltd. (Shanghai, China), and used as received.

\subsection{Methods}

Fourier transform infrared (FTIR) spectra were recorded on a Bruker Tensor27 FTIR spectrometer (Bruker Co., Ltd., Karlsruhe, Germany) in the range of $4000-500 \mathrm{~cm}^{-1}$ using the thin WPU films (less than $20 \mu \mathrm{m}$ in thickness) prepared by coating SDB-WPU emulsions on a potassium bromide ( $\mathrm{KBr})$ flake and then evaporating water by heating under an infrared lamp.

Ultraviolet-visible (UV-vis) spectra of SDB and WPU dispersion were measured by UV-3600 spectrophotometer (Shimadzu Co., Ltd., Kyoto, Japan) in dimethylformamide (DMF) and water at 298 K. UV-vis spectra of WPU films were recorded on UV-vis-NIR spectrometer (Shimadzu Co., Ltd., Kyoto, Japan) ranging from $240 \mathrm{~nm}$ to $1200 \mathrm{~nm}$ at $298 \mathrm{~K}$.

Dynamic light scattering (DLS): The particle size distribution of WPU emulsion were carried out on a Zetasizer Nano ZS-90 (Malvern Co., Ltd., Worcestershire, the United Kongdom) by dynamic light scattering (DLS) at room temperature.

Gel permeation chromatography (GPC) analyses were investigated by a Waters GPC instrument system (Waters Co., Ltd., Milford, Massachusetts, America) and calibrated with linear polystyrene, at a constant column temperature of $35^{\circ} \mathrm{C}$ using tetrahydrofuran (THF) as eluent with a flow rate of $0.6 \mathrm{~mL} / \mathrm{min}$.

Differential scanning calorimetric (DSC) curves were recorded via a Mettler-Toledo DSC (Mettler-Toledo Co., Ltd., Zurich, Switzerland) at a constant heating rate of $10{ }^{\circ} \mathrm{C} / \mathrm{min}$ from $-65^{\circ} \mathrm{C}$ $-180^{\circ} \mathrm{C}$ under $\mathrm{N}_{2}$ atmosphere.

Thermogravimetric analysis (TGA) curve was collected by Shimadzu TGA-50 (Shimadzu Co., Ltd., Kyoto, Japan) under $\mathrm{N}_{2}$ atmosphere at a constant heating rate of $10{ }^{\circ} \mathrm{C} / \mathrm{min}$ from $25^{\circ} \mathrm{C}$ to $700{ }^{\circ} \mathrm{C}$. 
WPU films were prepared by pouring WPU emulsions onto some polytetrafluoroethylene panels, and the panels were left at $25^{\circ} \mathrm{C}$ for $48 \mathrm{~h}$ to obtain a series of homogeneous thin films with a thickness of $1 \mathrm{~mm}$. The as obtained films were characterized without further annealing process.

The migration ratio $(\mathrm{Mp})$ was used to evaluate migration resistance of SDB-WPU. A glass plate was coated with SDB-WPU latex to form uniform film and divided into two areas (Area A and Area B), as shown in Scheme 1. Area A was clamped by a watch glass tightly, while Area B was exposed to the air. Then, the glass plate was kept at $60^{\circ} \mathrm{C}$ for $24 \mathrm{~h}$. The films in Area A and Area B were selected and dissolved into DMF at the same concentration and the absorbance was measured by UV-3600 spectrophotometer. Mp was calculated using the followed formula:

$$
\mathrm{Mp}=\left[\left(\mathrm{A}_{\operatorname{maxB}}-\mathrm{A}_{\max \mathrm{A}}\right) / \mathrm{A}_{\max \mathrm{A}}\right] \times 100 \%
$$

where $A_{\max }$ and $A_{\max B}$ are the maximum absorbance $\left(A_{\max }\right)$ of the SDB-WPU in DMF in Area A and Area B, respectively.

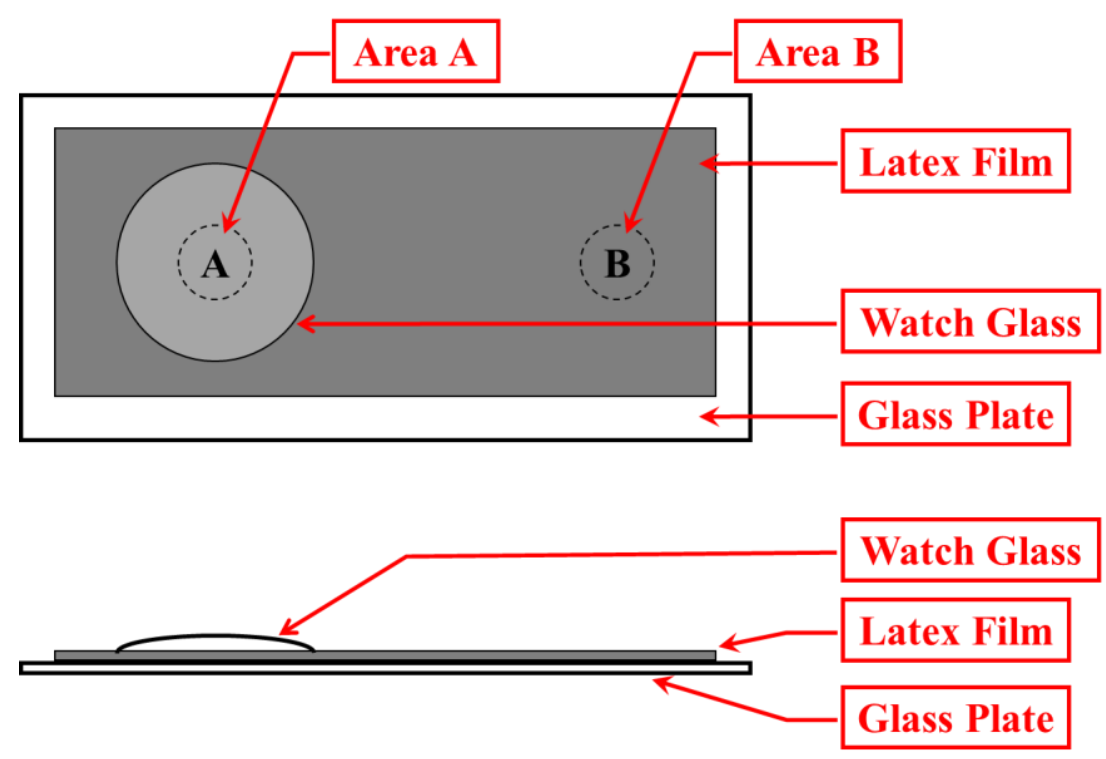

Scheme 1. Evaluation model for thermal migration of the dye.

Preparation of the black coatings: SDB-WPU, defoamer, thickener, leveling agent and deionized water were added into a dispersion machine. After stirring at high speed until a well-blended latex forms and then being left to stand for $30 \mathrm{~min}$, the latex was sprayed on the surface of steel plate and kept at $100{ }^{\circ} \mathrm{C}$ for $20 \mathrm{~min}$.

The physical properties of the SDB-WPU black coatings were evaluated according to standard test methods (impact strength GB/T 1732-93, Gloss GB/T 1743-89, adhesion force GB/T 1720-89, pencil hardness GB/T 6739-2006, and water resistance GB/T 23999-2009).

\subsection{Synthesis of SDB-WPUs}

The preparation processes of SDB-WPUs are shown in Scheme 2. IPDI and PTMG $(\mathrm{Mn}=2000)$ were added to a three-neck round-bottom flask (specific mass ratios are presented in Table 1). Then, the mixture was heated at $90^{\circ} \mathrm{C}$ for $2 \mathrm{~h}$ under an $\mathrm{N}_{2}$ atmosphere (NCO content was determined using a standard di- $n$-butylamine titration test method [27]). Subsequently, the mixture was cooled down to $80^{\circ} \mathrm{C}$; a specified amount of DMPA was added; and it was again heated to $80^{\circ} \mathrm{C}$ for approximately $2 \mathrm{~h}$ until the content of the $\mathrm{NCO}$ group in the mixture reached the expected theoretical value. The calculated amounts of BDO and SDB were added at $70{ }^{\circ} \mathrm{C}$ and allowed to react for $4 \mathrm{~h}$ with a trace amount of DBTDL $(0.05-0.1 \mathrm{wt} \%)$ as a catalyst. A moderate amount of acetone was required at this stage to 
reduce the viscosity in the course of polymerization (the weight ratio of prepolymer and acetone is 7:3). TEA as a neutralization agent (neutralization ratio is $100 \%$ ) was added at $40{ }^{\circ} \mathrm{C}$ to react with carboxyl group for $5 \mathrm{~min}$ to form a NCO-terminated WPU prepolymer (the molar ratio of $-\mathrm{NCO}$ and $-\mathrm{OH}$ is around 1-1.1). Finally, specific deionized water was poured into the mixture with the shearing rate of $3000 \mathrm{r} / \mathrm{min}$ to form WPU emulsion. A black aqueous dispersion was obtained after the acetone was removed from the WPU emulsion using a rotary evaporator in vacuum. The solid content of the obtained WPU emulsion was approximately $30 \mathrm{wt} \%$. By this method, a series of SDB-WPUs were synthesized, as illustrated in Table 1.<smiles>CC1(C)CC([N+](=O)[O-])CC(C)(CN=O)C1</smiles>

IPDI

$$
\begin{array}{cc}
\mathrm{HO}+\mathrm{CH}_{2} \mathrm{CH}_{2} \mathrm{CH}_{2} \mathrm{CH}_{2} \mathrm{O}+\mathrm{H} & \begin{array}{c}
\mathrm{CH}_{n} \\
\mathrm{HOCH}_{2} \mathrm{CCH}_{2} \mathrm{OH} \\
\mathrm{COOH}
\end{array} \\
\text { PTMG2000 } & \text { DMPA }
\end{array}
$$

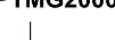

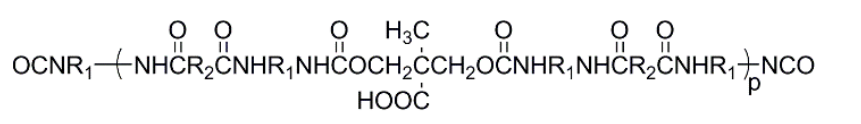

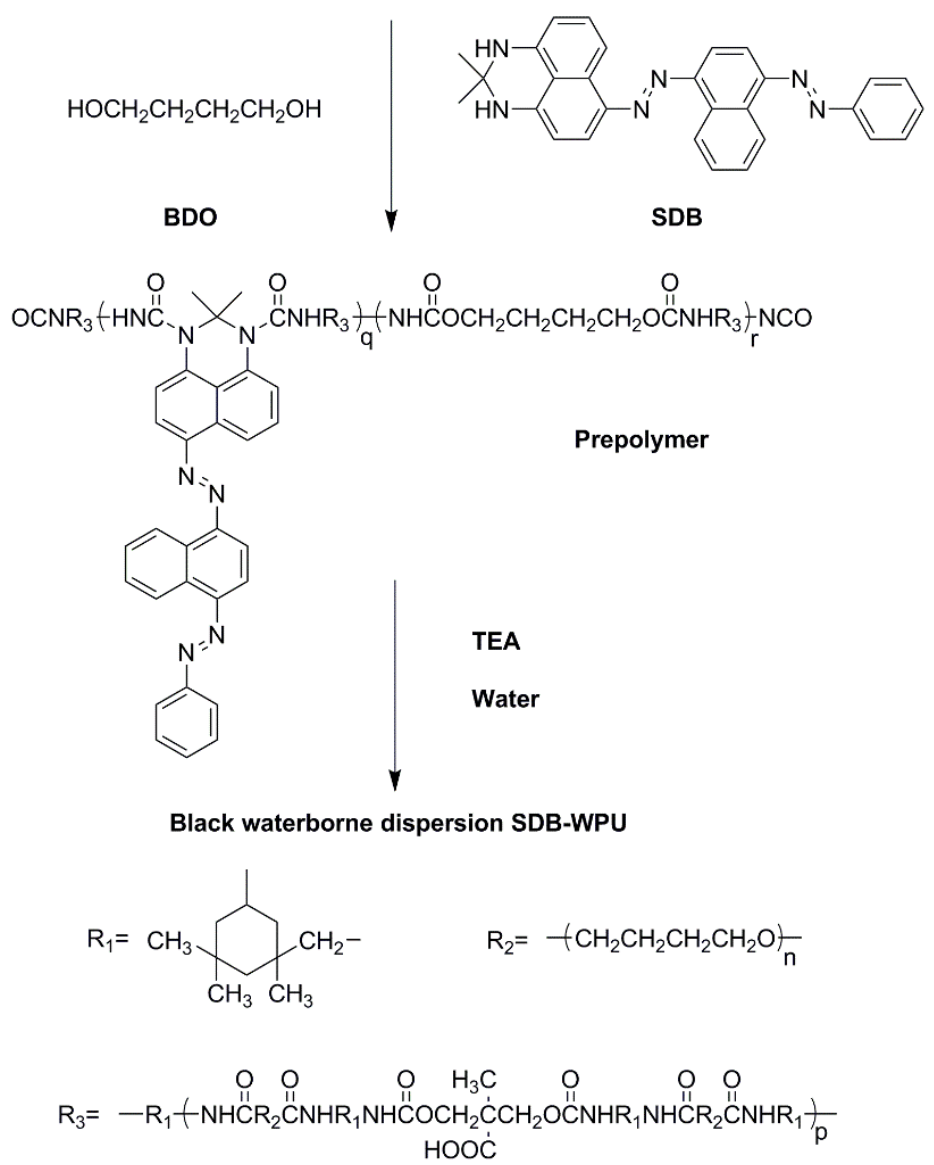

Scheme 2. Synthetic processes of SDB-WPU (Sudan Black B-waterborne polyurethanes). 
Table 1. The specific ratio of each component in SDB-WPUs (Sudan Black B-waterborne polyurethanes).

\begin{tabular}{cccccccc}
\hline Sample & $\begin{array}{c}\text { Polymeric } \\
\text { Diol }\end{array}$ & $\begin{array}{c}\text { Polymeric } \\
\text { Diol /g }\end{array}$ & IPDI /g & DMPA /g & SDB /g & BDO /g & $\begin{array}{c}\text { SDB } \\
\mathbf{( w t} \%)\end{array}$ \\
\hline SDB-WPU1 & PTMG & 25 & 12 & 2.3 & 0.42 & 1.8 & $1 \%$ \\
SDB-WPU2 & PTMG & 25 & 12 & 2.3 & 0.83 & 1.7 & $2 \%$ \\
SDB-WPU4 & PTMG & 25 & 12 & 2.3 & 1.7 & 1.55 & $4 \%$ \\
SDB-WPU6 & PTMG & 25 & 12 & 2.3 & 2.6 & 1.4 & $6 \%$ \\
SDB-WPU-PTMG & PTMG & 25 & 12 & 2.3 & 0.83 & 1.7 & $2 \%$ \\
SDB-WPU-PPG & PPG & 25 & 12 & 2.3 & 0.83 & 1.7 & $2 \%$ \\
SDB-WPU-PCL & PCL & 25 & 12 & 2.3 & 0.83 & 1.7 & $2 \%$ \\
SDB-WPU-PBA & PBA & 25 & 12 & 2.3 & 0.83 & 1.7 & $2 \%$ \\
\hline
\end{tabular}

\section{Results and Discussion}

\subsection{UV-Vis Spectra of SDB}

Sudan black B (SDB) is a highly coloration-efficient and cost-effective dye, with high molar absorptivity. The UV-vis spectra of SDB with different concentrations are measured in $N, N$-dimethylformamide (DMF). As Figure 1a shows, SDB has an almost total absorption in the visible region with an intense absorbance around $621 \mathrm{~nm}$ and a minor absorbance centered at $428 \mathrm{~nm}$, indicating that SDB solutions are nearly blue-black in dilute solution. Obviously, the maximum absorbance $\left(\mathrm{A}_{\max }\right)$ at $621 \mathrm{~nm}$ intensifies from 0.159 to 1.235 as the concentration of SDB in DMF increases from $2 \mathrm{mg} / \mathrm{L}$ to $20 \mathrm{mg} / \mathrm{L}$ (Figure 1b), which lines up with Beer-Lambert Law that can be used to calculate the SDB concentration in SDB-WPU.
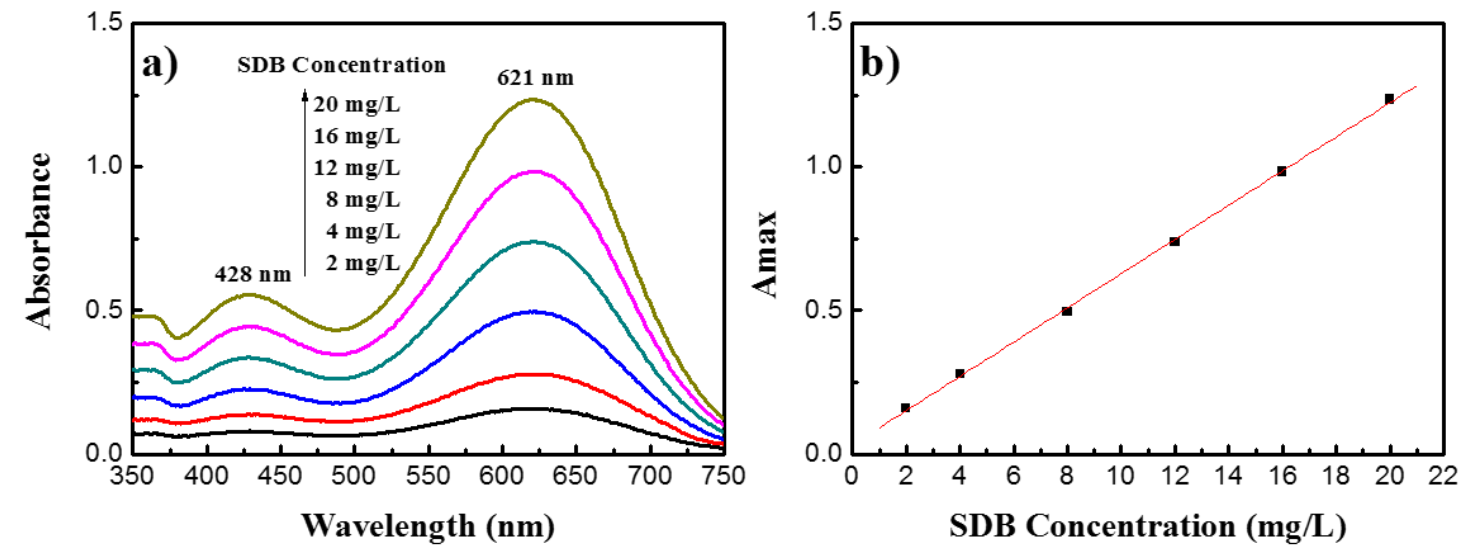

Figure 1. (a) UV-vis absorption spectra of SDB (Sudan Black B) with different dye concentrations in DMF (dimethylformamide). (b) The linear relationship of the Amax (621 nm) with different dye concentration.

\subsection{Structural Analysis of SDB-WPUs}

SDB-WPUs were synthesized from the reaction between $-\mathrm{NH} /-\mathrm{OH}$ and $-\mathrm{NCO}$ groups according to previously reported polycondensation reaction (Scheme 2) [20,28]. Briefly, there are two main steps in the course of polymerization. One is the reaction of diols and diisocyanates to obtain prepolymers containing SDB. The other is the emulsifying process of the prepolymers with a high shear speed after trimethylamine is added. Figure 2 shows the FTIR spectra of SDB-WPUs with different ratios of SDB (0-6\%). Compared to WPU without SDB (WPU0), the characteristic absorption peak at $1595 \mathrm{~cm}^{-1}(\mathrm{~N}=\mathrm{N})$ appears and enhances with increasing SDB loadings. Meanwhile, the representative $\mathrm{N}-\mathrm{H}$ vibration at $3430 \mathrm{~cm}^{-1}$ disappears in all of the WPU films, suggesting that SDB has been covalently linked to the WPU chains. Other characteristic absorption peak assignments for SDB-WPUs include: $3325 \mathrm{~cm}^{-1}\left(v_{\mathrm{NH}}\right), 2860 \mathrm{~cm}^{-1}$ and $2940 \mathrm{~cm}^{-1}\left(v_{\mathrm{CH} 2}\right.$ and $\left.v_{\mathrm{CH} 3}\right), 1701 \mathrm{~cm}^{-1}\left(v_{\mathrm{C}=\mathrm{O}}\right)$, 
$1240 \mathrm{~cm}^{-1}\left(v_{\mathrm{C}-\mathrm{O}}\right.$ in carbamate group) and $1110 \mathrm{~cm}^{-1}\left(v_{\mathrm{C}-\mathrm{O}-\mathrm{C}}\right.$ in PTMG), indicating that SDB-WPUs were synthesized successfully.

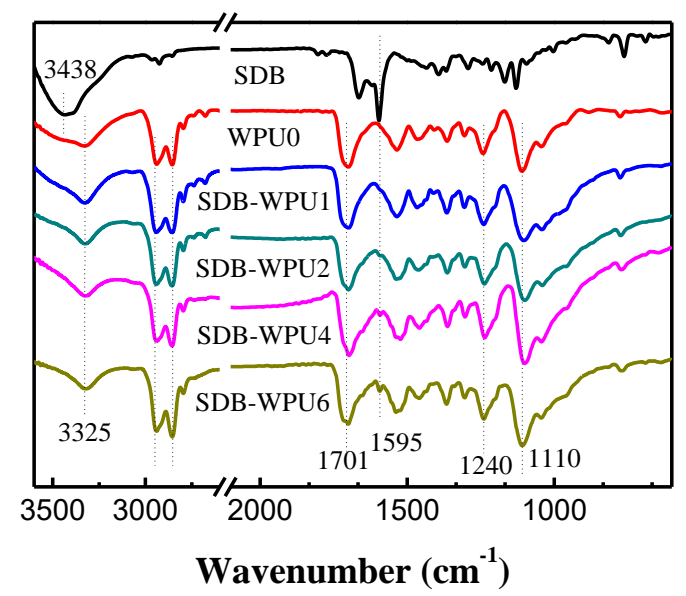

Figure 2. FTIR spectra of SDB and SDB-WPU with various dye contents on KBr plates.

To further demonstrate that SDB is chemically linked to polymeric main chains, the investigation on macroscopic migration of the SDB-WPU between water and solvent phases is conducted. The alteration of the color in two phases is recorded by digital camera at different moments, as illustrated in Figure 3. To water emulsion are added chloroform to illustrate whether SDB can be extracted. As Figure 3 shows, after stirring, chloroform does not immediately turn black. However, after 24 hours standing, there is no obvious change in chloroform with slight black, which are caused by few SDB-WPUs transferring from water to organic phase. As we all know, SDB as micromolecular dye has high mobility, which should migrate into water immediately after intense stirring because SDB is hydrophobic. Therefore, the slight change in chloroform ascribed to migration of SDB-WPU is reasonable, further indicating that SDB is covalently incorporated into WPUs. The mechanical stability in Table 2 also suggests that SDB is reacted into WPUs due to no obvious alteration in emulsion state, which means that no hydrophobic SDB aggregates precipitates after centrifugal sedimentation.

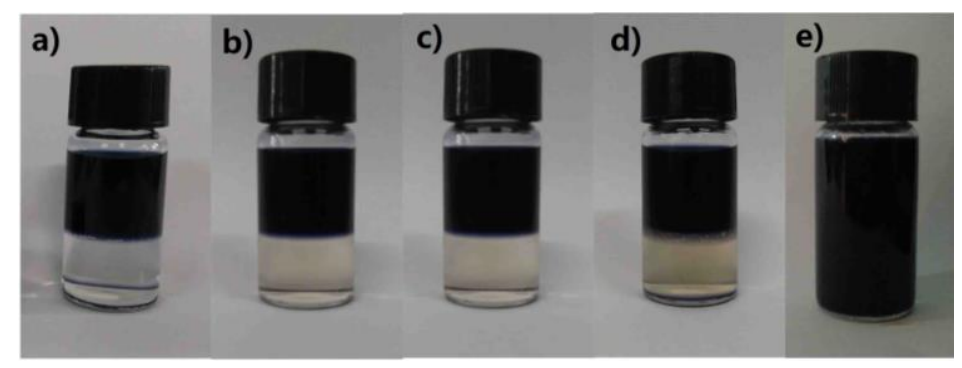

Figure 3. Graphs of: SDB-WPU2 (a-d); and SDB+WPU (physical mix of $2 \mathrm{wt} \%$ SDB and pure WPU) (e) migration between aqueous phase and $\mathrm{CH}_{3} \mathrm{Cl}$ phase at different moments $\left(\mathrm{t}_{\mathrm{s}}\right) .(\mathbf{a}) \mathrm{t}_{\mathrm{s}}=0 \mathrm{~h}$; $(\mathbf{b}) \mathrm{t}_{\mathrm{s}}=6 \mathrm{~h}$; (c) $t_{\mathrm{s}}=12 \mathrm{~h} ;(\mathbf{d}) \mathrm{t}_{\mathrm{s}}=24 \mathrm{~h} ;$ and (e) $\mathrm{t}_{\mathrm{s}}=5 \mathrm{~min}$.

\subsection{Statistical Properties of SDB-WPUs}

The specific ratio of each component is shown in Table 1 . The particle diameters measured by DLS of emulsions are shown in Table 2. All of the WPU dispersions exhibit tiny average particle size $(<50 \mathrm{~nm})$. As the SDB ratio increases from $1 \%$ to $6 \%$, the average particle size increases from $19.79 \mathrm{~nm}$ to $43.32 \mathrm{~nm}$, ascribed to the enhanced hydrophobicity of SDB-WPU due to multi-aromatic rings in SDB. Besides, multi-aromatic structures and large size of SDB may prevent polymeric chains from entangling to small radius. To the best of our knowledge, smaller particle sizes show better emulsion stability. 
After more than six months, the dispersion remains homogeneous without any precipitates (Table 2). Moreover, there is no obvious change in emulsion state after $30 \mathrm{~min}$ centrifugation at $3000 \mathrm{r} / \mathrm{min}$ (Table 2), which demonstrates that SDB-WPUs are mechanically stable.

Table 2. The various statistical properties of SDB-WPUs.

\begin{tabular}{cccccc}
\hline Sample & $\begin{array}{c}\text { Average } \\
\text { Particle Size }\end{array}$ & $\begin{array}{c}\text { Storage } \\
\text { Stability }\end{array}$ & $\begin{array}{c}\text { Mechanical } \\
\text { Stability }\end{array}$ & Mn $^{\mathbf{a}}$ & PDI $^{\mathbf{b}}$ \\
\hline SDB-WPU1 & $19.79 \mathrm{~nm}$ & Unchanged & Unchanged & 16,100 & 3.61 \\
SDB-WPU2 & $21.38 \mathrm{~nm}$ & Unchanged & Unchanged & 16,300 & 3.70 \\
SDB-WPU4 & $41.69 \mathrm{~nm}$ & Unchanged & Unchanged & 14,400 & 3.63 \\
SDB-WPU6 & $43.32 \mathrm{~nm}$ & Unchanged & Unchanged & 13,200 & 3.17 \\
SDB-WPU-PTMG & $21.38 \mathrm{~nm}$ & Unchanged & Unchanged & 16,300 & 3.70 \\
SDB-WPU-PPG & $19.21 \mathrm{~nm}$ & Unchanged & Unchanged & 16,000 & 2.79 \\
SDB-WPU-PCL & $13.40 \mathrm{~nm}$ & Unchanged & Unchanged & 18,900 & 2.85 \\
SDB-WPU-PBA & $13.97 \mathrm{~nm}$ & Unchanged & Unchanged & 17,400 & 2.67 \\
\hline
\end{tabular}

${ }^{a}$ Number, average molecular weights of SDB-WPUs measured in THF; ${ }^{b}$ Polydispersity index $\left(M_{\mathrm{w}} / M_{\mathrm{n}}\right)$.

The molecular weight information of SDB-WPUs is characterized by gel-permeation chromatography (GPC, Table 2). In Table 2, all of the SDB-WPUs show broad molecular weight distributions with polydispersity indices around $2-4$. It is worth noting that molecular weight information of SDB-WPUs is not very reliable due to the presence of extremely polar carboxylate and ammonium groups.

\subsection{DSC and TG Analyses}

Figure 4 shows the thermal properties of SBD-WPUs with different contents. From Differential Scanning Calorimetry (DSC) curves (Figure 4a) (all of the samples were measured without the elimination of the thermal history), a broad endothermic peak appears obviously in the range of $50-100{ }^{\circ} \mathrm{C}$ for all of the samples, which is not a typical glass transition, which usually shows a slope between two platforms [29]. The broad peak is due to the disappearance of short-range ordered structures in the hard segments [30]. There is a new endothermic peak around $125^{\circ} \mathrm{C}$ for SDB-WPU6, which is due to the damage of microcrystalline structures organized in the process of film formation. Thermogravimetric (TG) analysis is shown in Figure $4 \mathrm{~b}$. All films show three thermal decomposition courses. The slow descending slopes from the 80 to $250{ }^{\circ} \mathrm{C}$ due to the disappearance of small molecules such as triethylamine and water. The steep slopes showing in the $250{ }^{\circ} \mathrm{C}-350{ }^{\circ} \mathrm{C}$ region are the breakage of allophanate and carbamate bonds. The last stage appears in the $350{ }^{\circ} \mathrm{C}-460{ }^{\circ} \mathrm{C}$ region where $\mathrm{C}-\mathrm{C}$ bonds in the soft segment (PTMG) of WPUs decompose. It is noteworthy that SDB-WPU6 exhibits more clear decrease in the first decomposition stage. To make SDB-WPU6 (solid content is $\sim 32 \%$ ) disperse homogenously, more deionized water was added due to the incorporation of more rigid and hydrophobic SDB compared to other samples. Therefore, there may be more residual water in the film after being left at $25^{\circ} \mathrm{C}$ for $48 \mathrm{~h}$. With increasing SDB loadings, the maximum hard-segment decomposition temperature rises from $306^{\circ} \mathrm{C}$ to $314{ }^{\circ} \mathrm{C}$ by a derivative thermogravimetric analysis (DTGA) (Figure 4c), which may be caused by more and more rigid phenyl rings in the hard segments, while the maximum soft-segment decomposition temperature remains at $418^{\circ} \mathrm{C}$, indicating that there is microphase separation to some extent between soft segments and hard segments. 

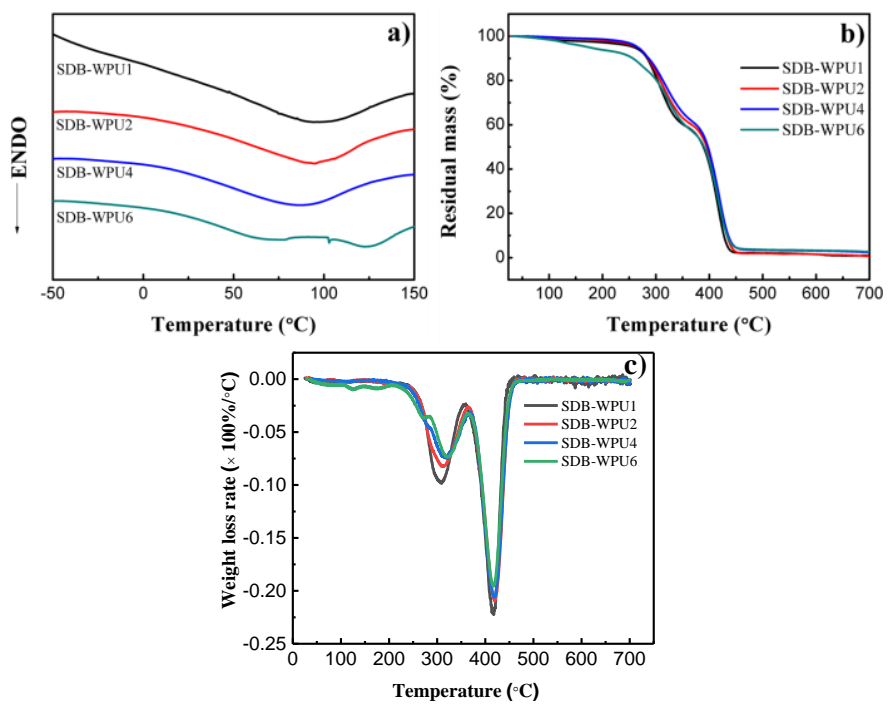

Figure 4. Thermal characterization of SDB-WPUs with various SDB contents via: DSC (a); TG (b); and DTGA (c) measurements.

\subsection{UV-Vis Spectra Analysis of SDB-WPUs}

Figure 5 shows the UV-vis spectra of SDB-WPUs. Compared to the UV-vis spectra of pure SDB in DMF solution, it is clearly found that, when SDB is introduced into the WPU chains, the maximum absorption of SDB shifts from $623 \mathrm{~nm}$ to $603 \mathrm{~nm}$, which likely results from the influence of conjugate effect between aromatic amino in SDB and allophanyl in WPUs, which weakens electron-donating ability of aromatic amino in SDB. It can be illustrated by dissolving SDB-WPU films in DMF solution, in which maximum absorption wavelength is almost consistent with the SDB-WPU aqueous emulsion, excluding the possible impact induced by the polarity of solvent. Figure $5 \mathrm{~b}$ shows the UV-vis spectra of SDB-WPU films. All of the SDB-WPU films exhibit complete, intense absorption in the visible region in comparison to solution state, which is almost pure black, as observed by the naked eye.
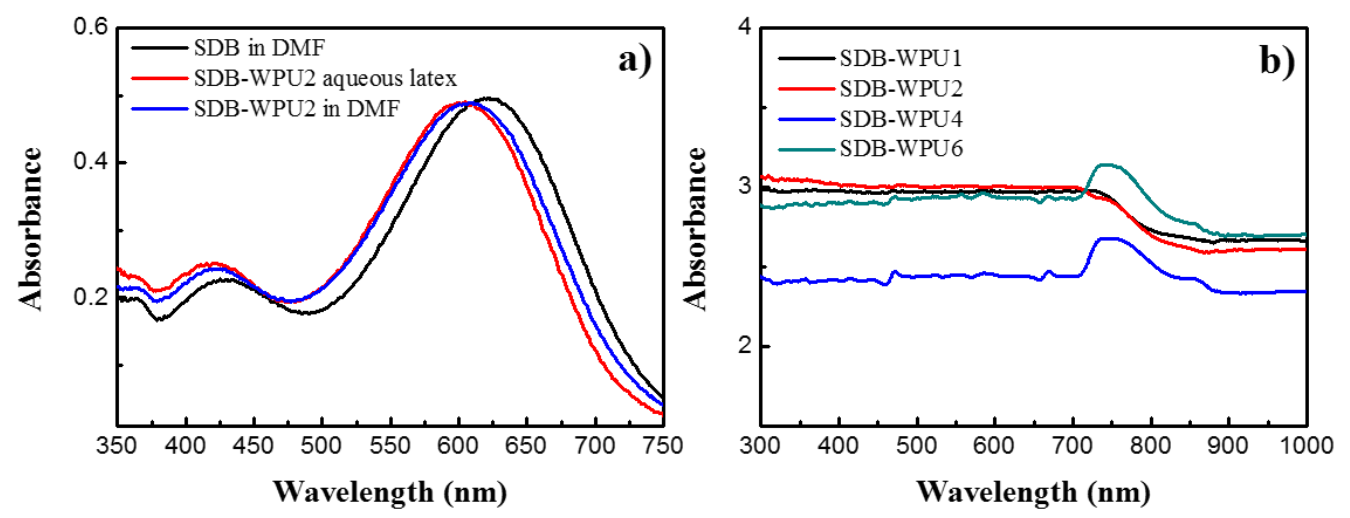

Figure 5. (a) UV-vis absorption spectra of SDB in DMF, SDB-WPU2 aqueous emulsion and SDB-WPU2 in DMF (blue) with the same concentration of SDB. (b) UV-vis absorption spectra of the SDB-WPU films dispersed in $\mathrm{BaSO}_{4}$.

\subsection{Analyses of SDB-WPUs with Different Polymeric Diols}

To investigate the influence of soft segments on physical properties of black WPUs, different polymeric diols (PTMG, PBA, PPG, PCL) are used to prepare WPUs with constant SDB content $(2 \%, w t / w t)$. All of the WPU emulsions show the particle diameters around 10-20 nm, suggesting 
the excellent dispersion, storage and mechanical stability (Table 2). All of the samples exhibit no clear change after centrifuging for $30 \mathrm{~min}$ at $3000 \mathrm{r} / \mathrm{min}$ or sitting for six months.

The FT-IR spectra of WPUs with different polymeric diols are presented in Figure 6. Consistent with the description above, SDB is covalently attached into WPU chains due to the disappearance of $\mathrm{N}-\mathrm{H}$ stretching vibration of SDB and the appearance of the representative $\mathrm{N}-\mathrm{H}$ vibration at $3325 \mathrm{~cm}^{-1}$ in polyether-based WPUs (SDB-WPU-PTMG and SDB-WPU-PPG) and at $3350 \mathrm{~cm}^{-1}$ in polyester-based WPUs (SDB-WPU-PCL and SDB-WPU-PBA). The differences between polyether-based WPUs and polyester-based WPUs may be ascribed to their different microenvironments, such as the different degree of microphase separation and amounts of hydrogen bonds. A similar phenomenon is presented in stretching vibration of $\mathrm{C}=\mathrm{O}\left(1730 \mathrm{~cm}^{-1}\right.$ in polyester-based WPUs and $1701 \mathrm{~cm}^{-1}$ in polyether WPUs). Other characteristic absorption peak assignments for SDB-WPUs with different polymeric diols are similar to Figure 2: $2860 \mathrm{~cm}^{-1}$ and $2940 \mathrm{~cm}^{-1}\left(v_{\mathrm{CH} 2}\right.$ and $\left.v_{\mathrm{CH} 3}\right), 1240 \mathrm{~cm}^{-1}\left(v_{\mathrm{C}-\mathrm{O}}\right.$ in carbamate group) and $1110 \mathrm{~cm}^{-1}\left(v_{\mathrm{C}-\mathrm{O}-\mathrm{C}}\right.$ in soft segments), suggesting that SDB-WPUs were synthesized successfully.

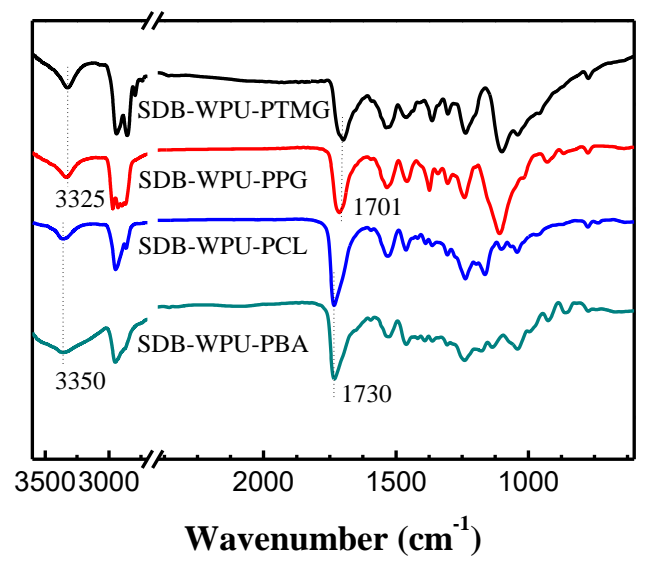

Figure 6. FT-IR spectra of SDB-WPUs with various polymeric diols on KBr plates.

The thermal properties of SDB-WPUs with various polymeric diols are characterized by DSC and TG curves (Figure 7). Similar results line up with the discussion above. The difference in DSC (Figure 7a) is that a typical endothermic peak appears at $40-50{ }^{\circ} \mathrm{C}$ in SDB-WPU-PCL and SDB-WPU-PBA due to the melting of crystalline structure of the polyester in PCL and PBA. There is a clear difference in third decomposition stage caused by different thermal resistance of polymeric diols and degree of microphase separation (Figure 7b) [31-33]. According to the TG curves, SDB-WPU-PTMG, with the highest starting and soft-segment decomposition temperatures, shows the best thermal resistance, while SDB-WPU-PBA exhibits the poorest thermal resistance. The remaining two kinds of WPUs have similar thermal resistances.

As we all know, dyes are physically mixed into polymeric coatings influenced by dispersants in that dyes tend to migrate from the coatings interior to aggregate on the coatings surface due to weak binding force. To evaluate the migration property of SDB-WPUs, the same experiments were carried out with the sample formed by physically mixing WPU with SDB (WPU+SDB) as a control. As provided in Table 3, Mp values of SDB-WPUs and WPU+SDB are $7 \%-8 \%$ and $31.0 \%$, respectively, manifesting that SDB-WPUs exhibit greater thermal-migration resistance than WPU+SDB. Shown in Scheme 3 are the models of thermal migration of dye-doped WPU and dye-incorporated WPU. SDB tends to migrate and aggregate to a certain area due to enhanced free volumes and weak binding force (Scheme 3a), which may cause inhomogeneous color distribution. Migration process occurs in both the interior and surface of SDB-WPU films. For example, SDB in the interior may migrate to surface and then aggregate to an area in the surface leading to the inhomogeneity of black. However, the mobility of SDB is confined due to the covalent binding of $-\mathrm{NH}$ in SDB and -NCO, resulting in homogeneous dispersity of SDB in WPU. The black SDB-WPU obtained by covalent link with excellent 
migration-resistance property can be applied effectively in polyurethane coatings, while traditional preparation method via mixing polyurethane resin with micromolecular dyes cannot easily achieve such remarkable migration resistance.
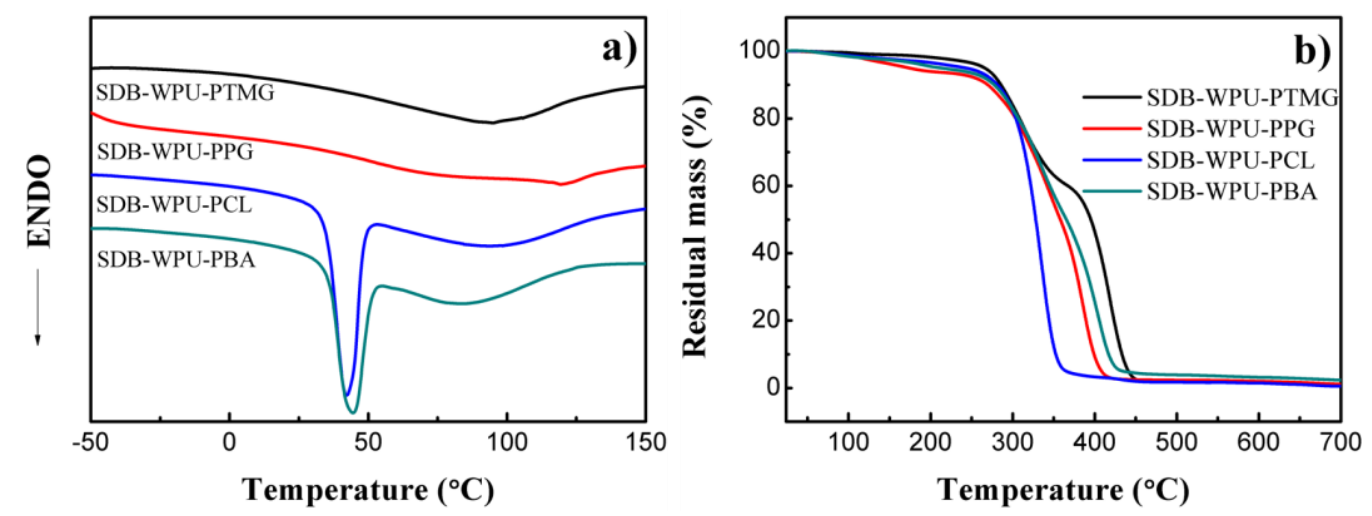

Figure 7. Thermal characterization of SDB-WPUs with various polymeric diols via: DSC (a); and TG (b) measurements.

Table 3. Thermal-migration property of SDB-WPUs and WPU+SDB.

\begin{tabular}{cccc}
\hline Samples & $\mathbf{A}_{\mathbf{1}}{ }^{\mathbf{a}}$ & $\mathbf{A}_{\mathbf{2}}{ }^{\mathbf{b}}$ & $\mathbf{M}_{\mathbf{p}} \mathbf{( \% )} \mathbf{c}^{\mathbf{c}}$ \\
\hline WPU+SDB & 0.332 & 0.435 & $31.0 \%$ \\
SDB-WPU-PTMG & 0.309 & 0.332 & $7.4 \%$ \\
SDB-WPU-PPG & 0.276 & 0.298 & $8.0 \%$ \\
SDB-WPU-PCL & 0.327 & 0.351 & $7.3 \%$ \\
SDB-WPU-PBA & 0.252 & 0.271 & $7.5 \%$
\end{tabular}

a maximum absorbance of SDB-WPUs in area $\mathrm{A} ;{ }^{\mathrm{b}}$ maximum absorbance of SDB-WPUs in area $\mathrm{B} ;{ }^{\mathrm{c}}$ migration ratio of SDB-WPUS.

a)

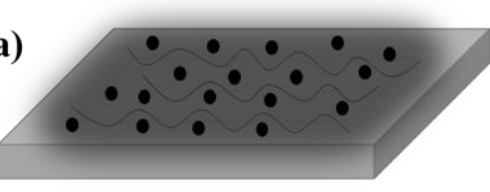

b)

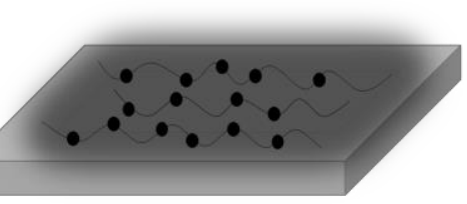

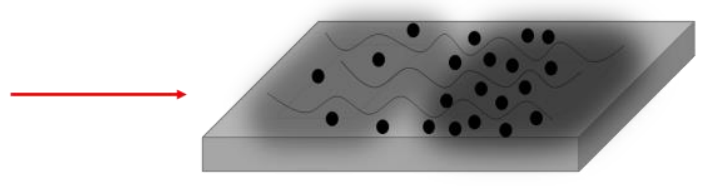
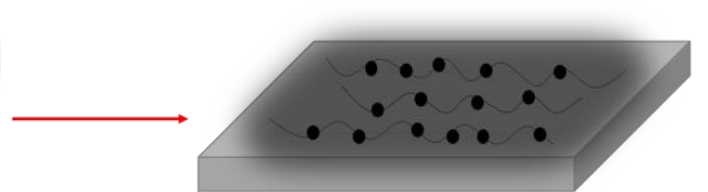

Scheme 3. Thermal migration models of: dye-doped (not covalently bonded) WPUs (WPU+SDB) (a); and dye-linked WPUs (SDB-WPUs) (b).

\subsection{Application in Metal Coatings}

Black SDB-WPU coatings can easily be prepared by spraying the mixture on the metal surface after compounded with other waterborne resins and coatings additives (Table 4). The coating properties of the SDB-WPUs are illustrated in Table 5. All of the film coatings show smooth and bubble-free surfaces with glossiness around 80-90. Because of the chemically linking reaction, SDB is uniformly distributed into the polyurethanes without dyes aggregating and phase separation (Figure 8), resulting in excellent coatings performance. To further investigate the properties of SDB-WPU coatings, adhesion force, pencil hardness, impact strength and water resistance are tested. Slight difference can be observed in 
these properties, attributed to the change of polymeric diols, which are able to significantly influence degree of microphase separation, flexibility, rigidity and crystallinity. Consequently, different black WPU coatings with SDB linked chemically may be developed by changing the kind of polymeric diol to cater to a specific applied situation.

Table 4. Formulation of black SDB-WPU coatings.

\begin{tabular}{ccc}
\hline Entry & Function & wt $\%$ \\
\hline SDB-WPU & Resin & 95 \\
BYK-025 & Defoamer & 0.5 \\
BYK-331 & Leveling additive & 0.3 \\
ACRYSOLTM RM-8W & Thickener & 1.2 \\
Deionized water & - & 3 \\
Total & - & 100 \\
\hline
\end{tabular}

Table 5. The properties of black waterborne polyurethane coatings with various polymer diols.

\begin{tabular}{ccccc}
\hline Property & SDB-WPU-PTMG & SDB-WPU-PPG & SDB-WPU-PCL & SDB-WPU-PBA \\
\hline Appearance & Smooth, & Smooth, & Smooth, & Smooth, \\
Gloss $\left(60^{\circ}\right)$ & No bubbles & No bubbles & No bubbles & No bubbles \\
Adhesion force (grade) & 83 & 83 & 86 & 87 \\
Pencil hardness & 0 & 1 & 0 & 0 \\
Impact strength $(\mathrm{kg} / \mathrm{cm})$ & $2 \mathrm{~B}$ & $3 \mathrm{~B}$ & $\mathrm{~B}$ & $2 \mathrm{~B}$ \\
Water resistance $(24 \mathrm{~h})$ & Unchanged & Unchanged & Unchanged & Unchanged \\
\hline
\end{tabular}

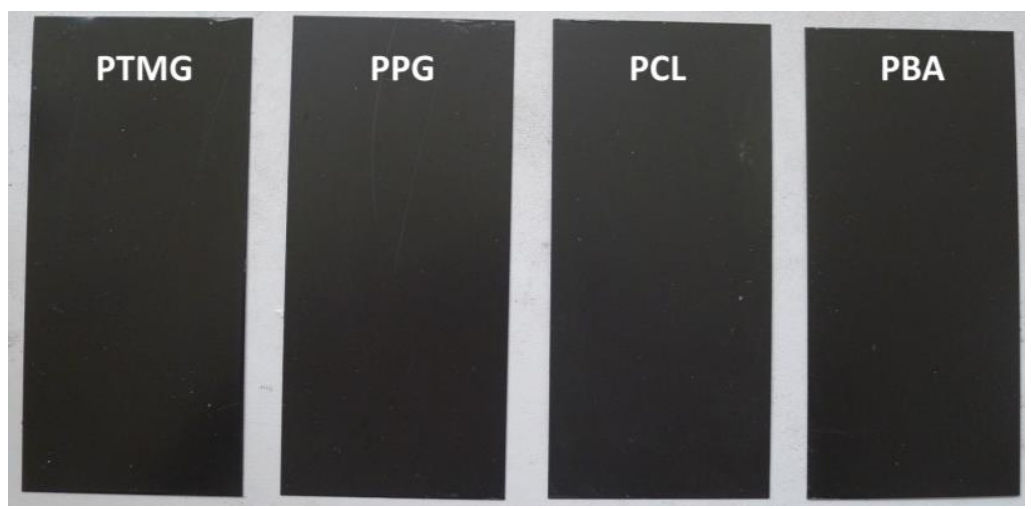

Figure 8. Black SDB-WPU coatings on the surface of steel plate with different soft segments: PTMG (polytetramethylene ether glycol); PPG (polypropylene glycol); PCL (polycaprolactone glycol); and PBA (poly-1, 4-butylene adipate glycol).

\section{Conclusions}

In summary, a series of black WPUs from Sudan black B (SDB) were prepared. The obtained SDB-WPU emulsions show remarkable storage and mechanical stability. Compared to the traditional method by physically mixing dyes with polymeric substrates, SDB-WPUs also exhibit excellent thermal-migration resistance and color fastness, in that SDB is chemically linked to WPU chains. Besides, incorporation of SDB does not obviously change the thermal properties of WPUs. By altering different polymeric diols, all of the SDB-WPUs show some differences in glossiness and adhesion force but maintain their excellent storage and mechanical stability, and great thermal resistance. Therefore, different black WPU coatings with SDB linked chemically may be developed by changing the kind of polymeric diol to cater to a specific applied situation. 
Acknowledgments: The authors would like to thank the National High Technology Research and Development Program of China (No.2015AA033903) for financial support.

Author Contributions: Tao Wang and Xingyuan Zhang conceived and designed the experiments; Tao Wang and Wei Sun carried out synthesis and analyzed the data; Haiyan $\mathrm{Xu}$ and Fei $\mathrm{Xu}$ contributed to reagents and laboratory equipment; and Tao Wang and Xingyuan Zhang wrote the manuscript. All authors took part in the discussion and revisions.

Conflicts of Interest: The authors declare no conflict of interest.

\section{References}

1. Ventura-Camargo, B.C.; De Angelis, D.F.; Marin-Morales, M.A. Assessment of the cytotoxic, genotoxic and mutagenic effects of the commercial black dye in Allium cepa cells before and after bacterial biodegradation treatment. Chemosphere 2016, 161, 325-332. [CrossRef] [PubMed]

2. Nabil, G.M.; El-Mallah, N.M.; Mahmoud, M.E. Enhanced decolorization of reactive black 5 dye by active carbon sorbent-immobilized-cationic surfactant (AC-CS). J. Ind. Eng. Chem. 2014, 20, 994-1002. [CrossRef]

3. Zhuge, J.; Yu, Z.; Gao, J.; Zheng, D. Influence of color coatings on aircraft surface ice detection based on multi-wavelength imaging. Optoelectron. Lett. 2016, 12, 144-147. [CrossRef]

4. Haroun, A. Evaluation of modified leather dyeing technique using black dyestuffs from the economical view. Dyes Pigments 2005, 67, 215-221. [CrossRef]

5. Han, L.; Islam, A.; Chen, H.; Malapaka, C.; Chiranjeevi, B.; Zhang, S.; Yang, X.; Yanagida, M. High-efficiency dye-sensitized solar cell with a novel co-adsorbent. Energ. Environ. Sci. 2012, 5, 6057-6060. [CrossRef]

6. Ozawa, H.; Shimizu, R.; Arakawa, H. Significant improvement in the conversion efficiency of black-dye-based dye-sensitized solar cells by cosensitization with organic dye. RSC Adv. 2012, 2, 3198-3200. [CrossRef]

7. Wang, L.; Pan, X.; Wang, F.; Yang, L.; Liu, L. Structure-properties relationships investigation on the azo dyes derived from benzene sulfonamide intermediates. Dyes Pigments 2008, 76, 636-645. [CrossRef]

8. Adegoke, O.A.; Kyu, J.K.; Mukherjee, A. In vitro genotoxicity evaluation of 4-carboxyl-2, 6-dinitrophenylazohydroxynaphthalenes using human lymphocytes. Food. Chem. Toxicol. 2012, 50, 936-941. [CrossRef] [PubMed]

9. Mittal, A.; Thakur, V.; Gajbe, V. Adsorptive removal of toxic azo dye amido black $10 \mathrm{~b}$ by hen feather. Environ. Sci. Pollut. R. 2013, 20, 260-269. [CrossRef] [PubMed]

10. Alemdaroglu, F.E.; Alexander, S.C.; Ji, D.; Prusty, D.K.; Borsch, M.; Herrmann, A. Poly (bodipy) s: A new class of tunable polymeric dyes. Macromolecules 2009, 42, 6529-6536. [CrossRef]

11. Miltsov, S.; Karavan, V.; Goikhman, M.; Podeshvo, I.; Gómez-de Pedro, S.; Puyol, M.; Alonso-Chamarro, J. Synthesis of bis-aminosubstituted indocyanine dyes for their use in polymeric compositions. Dyes Pigments 2014, 109, 34-41. [CrossRef]

12. Tang, B.; Zhang, S.; Yang, J.; Liu, F. Synthesis of a novel water-soluble crosslinking polymeric dye with good dyeing properties. Dyes Pigments 2006, 68, 69-73. [CrossRef]

13. Marechal, E. Polymeric dyes—synthesis, properties and uses. Prog. Org. Coat. 1982, 10, 251-287. [CrossRef]

14. Marechal, E. Macromolecular dyes. Oligomeric and unsaturated dyes for UV curing. Pure Appl. Chem. 1980, 52, 1923-1928. [CrossRef]

15. Libert, C.; Marechal, E. Synthesis of macromolecules containing color-forming monomers. Eur. Poly. J. 1980, 16, 951-956. [CrossRef]

16. Deng, Y.; Tang, B.; Zhao, H.; Xu, J.; Xiao, J.; Zhang, X.; Xu, H.; Zhang, S. Dyeing method and properties of polymaleic acid dyes on cotton. Color. Technol. 2013, 129, 144-149. [CrossRef]

17. Zhou, X.; Tang, B.; Zhang, S. A facile synthesis of poly (acrylanilide-co-acrylic acid). Asian J. Chem. 2013, $25,3247$.

18. Xu, H.; Tang, B.T.; Zhang, S.F. Synthesis and dyeing performance of a novel polycarboxylic acid azo dye. Chin. Chem. Lett. 2011, 22, 424-426. [CrossRef]

19. Zamanloo, M.R.; nasser Shamkhali, A.; Alizadeh, M.; Mansoori, Y.; Imanzadeh, G. A novel barbituric acid-based azo dye and its derived polyamides: Synthesis, spectroscopic investigation and computational calculations. Dyes Pigments 2012, 95, 587-599. [CrossRef] 
20. Zhou, C.; Xie, T.; Zhou, R.; Trindle, C.O.; Tikman, Y.; Zhang, X.; Zhang, G. Waterborne polyurethanes with tunable fluorescence and room-temperature phosphorescence. ACS Appl. Mater. Interfaces 2015, 7, 17209-17216. [CrossRef] [PubMed]

21. Madbouly, S.A.; Xia, Y.; Kessler, M.R. Rheological behavior of environmentally friendly castor oil-based waterborne polyurethane dispersions. Macromolecules 2013, 46, 4606-4616. [CrossRef]

22. Kim, B.K.; Lee, J.C. Waterborne polyurethanes and their properties. J. Poly. Sci. Poly. Chem. 1996, 34, 1095-1104. [CrossRef]

23. Mao, H.; Wang, C.; Wang, Y. Synthesis of polymeric dyes based on waterborne polyurethane for improved color stability. New J. Chem. 2015, 39, 3543-3550. [CrossRef]

24. Mao, H.; Wang, Y.; Yao, D.; Wang, C.; Sun, S. Synthesis of blocked waterborne polyurethane polymeric dyes with tailored molecular weight: Thermal, rheological and printing properties. RSC Adv. 2016, 6, 56831-56838. [CrossRef]

25. Hu, X.; Zhang, X.; Liu, J.; Dai, J. Synthesis, characterization and fluorescence performance of a waterborne polyurethane-based polymeric dye. J. Lumin. 2013, 142, $23-27$.

26. Mao, H.; Yang, F.; Wang, C.; Wang, Y.; Yao, D.; Yin, Y. Anthraquinone chromophore covalently bonded blocked waterborne polyurethanes: Synthesis and application. RSC Adv. 2015, 5, 30631-30639. [CrossRef]

27. ASTM International. Available online: https://www.astm.org/Standards/D2572.htm (accessed on 16 September 2017).

28. Bai, C.Y.; Zhang, X.Y.; Dai, J.B.; Li, W.H. A new UV curable waterborne polyurethane: Effect of C=C content on the film properties. Prog. Org. Coat. 2006, 55, 291-295. [CrossRef]

29. Wang, T.; Zhang, X.; Deng, Y.; Sun, W.; Wang, Q.; Xu, F.; Huang, X. Dual-emissive waterborne polyurethanes prepared from naphthalimide derivative. Polymers 2017, 9, 411. [CrossRef]

30. Seymour, R.W.; Cooper, S.L. Thermal analysis of polyurethane block polymers. Macromolecules 1973, 6, 48-53. [CrossRef]

31. Xiao, Y.; Jiang, L.; Liu, Z.; Yuan, Y.; Yan, P.; Zhou, C.; Lei, J. Effect of phase separation on the crystallization of soft segments of green waterborne polyurethanes. Polym. Test. 2017, 60, 160-165. [CrossRef]

32. Yang, Z.; Wu, G.; Zhang, H. Effects of the reagent molar ratio on the phase separation and properties of waterborne polyurethane for application in a water-based ink binder. J. Appl. Polym. Sci. 2017, 134, 45406. [CrossRef]

33. Čulin, J.; Andreis, M.; Šmit, I.; Veksli, Z.; Anžlovar, A.; Žigon, M. Motional heterogeneity and phase separation of functionalized polyester polyurethanes. Eur. Polym. J. 2004, 40, 1857-1866. [CrossRef] 